\title{
CO-REGULATION PROCESSES WITHIN INTERACTIVE DYNAMICS: INSIGHTS FROM SECOND GRADERS' COOPERATIVE WRITING
}

\author{
Katia Lehraus, Géry Marcoux \\ University of Geneva, Switzerland \\ E-mail: Katia.Lehraus@unige.ch, Gery.Marcoux@unige.ch
}

\begin{abstract}
This research aims at analyzing the features of interactive dynamics in second graders 'peer interactions (age 7-8) during cooperative writing in classroom settings. Focused on in-depth qualitative analyses of videotaped data, four pupil pairs' interactions have been examined in light of three dimensions: social, cooperative and cognitive. Within two main types of dynamics (favoring vs. not favoring learning), conjectures have been drawn about co-regulation processes in peer learning. While negative dynamics have shown to be detrimental for the cognitive processing of the task, thus needing teacher contextual regulation, positive dynamics have revealed three forms of teamwork, labelled self-reliant, autonomous and dependent. The results show that young learners, even when engaged in positive dynamics, are not always able to co-regulate peer learning. These findings call for teacher's careful observation in order to scaffold learners' cognitive processing.
\end{abstract}

Keywords: collaborative writing, cooperative learning, interactive dynamics, learning processes, qualitative analysis.

\section{Towards Socially Constructed Learning}

Most educational systems advise fostering peer interaction in order to enhance learning. This recommendation is rooted in contemporary theories assuming social interaction to be a key factor in informal and formal learning (e.g., Crahay, Dutrévis, \& Marcoux, 2015). Cognitive development has been defined as self-organization of actions and mental operations running through mechanisms of assimilation, accommodation and equilibration (Piaget, 1975). Yet learning occurs mostly in a social environment, so this definition has been developed in light of notions like 'zone of proximal development' (Vygotsky, 1934/1962) and 'scaffolding' (Bruner, 1987/2015). Learning can be seen as information coordination, which is the most effective when a task is situated in a learner's zone of proximal development and when the teacher, or a more competent peer, scaffolds the learner's proceeding on task via social interaction.

Social mediation takes various forms and can foster learning through processes like modeling (Bandura, 2000), collaboration or viewpoints' confrontation (Doise \& Mugny, 1997), and stimulates diverse ways of participating in a learning community (Lave \& Wenger, 1991). Interactions lead partners to 'think aloud' and thus develop metacognitive reflection by debate, mutual questioning or explaining of strategies. Hence through social interaction, learning takes place on interpersonal level first, then can be internalized on intrapersonal level (Vygotsky, 1934/1962; Bruner, 1987/2015).

Individual knowledge can also be seen as a part of human cognition, which is socially constructed, processed and distributed between persons and between persons and tools as well (Salomon, 1993). Knowing that the more information must be processed the more attention it requires, management of a complex task (like writing for beginners) implies high cognitive costs, thus simultaneous weakening of other processes (Fleuret \& Thibeault, 2016). In this view, 
Katia LEHRAUS, Géry MARCOUX. Co-regulation processes within interactive dynamics: Insights from second graders' cooperative writing

\begin{abstract}
PROBLEMS
OF EDUCATION

IN THE $21^{\text {st }}$ CENTURY Vol. 76, No. 4, 2018

426 the presence of a partner could alleviate cognitive load by distributing it among learners. Such a distribution could help to differentiate and select relevant information, as selectiveness is a complex competence requiring costly processes like assessing and decision making (Ledzinska \& Czerniawska, 2008).
\end{abstract}

\section{Peer Learning}

In peer learning it is presumed that social interactions could support learners in dealing with the cognitive aspects of school tasks. As a generic term, peer learning (Topping 2005) includes diverse forms of knowledge and competence building through active help among partners. In a perspective of self-regulated learning (Boekaerts, 1997, 2006), peer interaction is considered as one of potential resources helping learners to gain autonomy in schoolwork and thus become less dependent of teacher's supervision. From a teacher's viewpoint, peer learning could represent a valuable way to increase time on task and each pupil's responsibility in learning (Lehraus, 2015) as well as to engage interactive regulation processes (Allal \& Mottier Lopez, 2007).

Social regulation in learning is perceived as one of the multiple factors leading from hetero-regulation to self-regulation (Allal, 2001; Boekaerts \& Corno, 2005). As shown in a model of co-regulation of learning in school settings (Allal, 2015), self-regulation is embedded in interactive settings, with peer interactions as potential factors of co-regulation; these interactive settings are as well embedded in classroom situations, where teacher's interventions can regulate learners' learning; at top level, teachers can also regulate the contextual features of classroom situations. Furthermore, supportive tools (e.g., charts, lists) can be inserted at each level of this model, linking them together. At last however, actual learning results from coregulation processes taking place between sources of potential contextual regulation and each learner's internal self-regulating mechanisms (Allal, 2015).

As theories advocate peer learning potential, one could expect teachers to be using groupwork in everyday classroom practice. Yet in primary schools, a year-long observation in UK has shown that groupwork is infrequent (less than $12 \%$ of classroom time) compared to whole-class teaching and independent work (Baines, Blatchford, \& Webster, 2015). Similar results for time dedicated to groupwork were previously found in the USA, ranging from 7\% of classroom time (Pianta, Belsky, Houts, \& Morrison, 2007) to 15\% (Abrami, Poulsen, \& Chambers, 2004). Beyond quantity, findings concerning groupwork quality indicate that learners were mostly merely sitting in groups (Baines, Blatchford, \& Kutnick, 2003) rather than working together as teams. Additionally, when peer interaction happened to take place, problems in groupwork functioning were observed (Kutnick, Ota, \& Berdondini, 2008) as well as low quality interaction (e.g., sharing answers without argumentation) between primary school learners (Baines et al., 2015). However, according to the idea that group discussion can improve performance, a research has shown that under conditions of accurate collaboration between 10 year-old learners, it is the quality of argumentation (and not an individual's selfconfidence) that explains group performance (Trouche, Sander, \& Mercier, 2014).

\section{Problem of Research}

Teachers are prompted to organize interactive learning settings in classrooms, but only a minor part of them report frequent groupwork practice. Besides, good practice is more than just sitting in groups. Cooperative learning (Slavin, 1996, 2015) is a set of educational methods designed to promote participation and learning of all group members in a cooperatively shared undertaking (Davidson \& Worsham, 1992; for an overview of methods, see Sharan, 1999). For more than three decades, cooperative learning methods and their beneficial effects on social and academic outcomes have been well documented (for meta-analyses, see Johnson, Maruyama, Johnson, Nelson, \& Skon, 1981; Roseth, Johnson, \& Johnson, 2008; Slavin, 1983, 1996). 
Literature shows that cooperative learning could help teachers to organize peer interaction in order to promote learning. However, benefits of cooperative learning do not occur automatically, and if the method is not properly implemented, considerable difficulties can happen, such as dysfunctional teams and learners' resistance to groupwork (Boruvkova \& Emanovsky, 2016). A recent survey has shown two main challenges for teachers (207 from 67 schools in Geneva, Switzerland) when implementing cooperative learning in primary school classrooms: their beliefs regarding learning, and pragmatic hindrances such as time and curriculum constraints (Buchs, Filippou, Pulfrey, \& Volpé, 2017).

Beyond multiple classroom implementation issues (Sharan, 2010), it is yet not clear whether even the youngest learners are able to work together in cooperatively structured peer learning, as studies in first grades of primary school are underrepresented in literature on cooperative learning. Focused on cooperative learning with young learners in Geneva, a pilot study has shown that second graders (age 7-8) were globally able to work together in structured cooperative settings (Lehraus, 2010, 2015). In this research, pupil pairs engaged in cooperative writing tasks without teacher help or supervision for a very large amount of time ( $92 \%$ of all devoted time to paired writing). Learners also displayed appropriate functioning by demonstrating huge commitment in on-task matter with the assigned partner in an interactive, mostly joint form of participation.

These findings draw a general picture of pupil pairs' global functioning during teamwork, the way it could be observed from a teacher's overall viewpoint. However, is the teacher able to detect to what extent pupil pairs' interactions are constructive, or not, for task completing as well as for individual learning? Could the teacher point out which forms of interactions are the most and the least helpful? What kind of difficulties hinder learners' interactive functioning and learning? And furthermore, when and how to intervene in order to regulate learners' interactive learning processes?

\section{Research Focus}

By examining empirical qualitative data of a pilot study on second graders' cooperative writing during quasi-ecological settings in classrooms (Lehraus, 2015), this research is focused on what can be learned about the quality of young learners' peer interactions and what conjectures could be drawn on this basis for teacher's scaffolding interventions during peer learning in writing.

Learning to write is a very complex task for beginners. Therefore, it could be supportive to provide learners with external resources - or tools, like checklists (Allal, 2015). Another facilitation could lay in collaborative working procedures, allowing learners to benefit from dialogue with peers (Yarrow \& Topping, 2001) and so promote peer regulation. Such opportunities of dialogue about writing, considered as an object per se and thus seen from outside, could foster development of metalinguistic competences by joint construction of representations about written language (Fleuret \& Thibeault, 2016). A research with preschoolers (Morin \& Montésimos-Gelet, 2003) revealed that children's metalinguistic comments during collaborative writing have had an important impact on appropriation of writing and on the quality of output written in triads.

Yet outcomes on learning do not materialize unless teachers structure peer interactions and prepare learners to work in groups efficiently (Johnson, Johnson, \& Johnson Holubec, 2002). Furthermore, taking time for cooperative skills training has shown to have positive effects on primary school learners' interactions and learning (Blatchford, Baines, Rubie-Davies, Basset, \& Chowne, 2006). In this research (Lehraus, 2015), in order to facilitate young learners' learning in writing, potential sources of contextual regulation (Allal, 2015) have been inserted at three levels: 1) by structuring classroom settings through a cooperative learning method (Johnson et al., 2002); 2) by including a cooperative skills training into the writing tasks; 3 ) by providing pupil groups with cooperatively co-constructed tools (e.g., checklists). 
Katia LEHRAUS, Géry MARCOUX. Co-regulation processes within interactive dynamics: Insights from second graders' cooperative writing

\begin{abstract}
PROBLEMS
OF EDUCATION

IN THE $21^{\text {st }}$ CENTURY

Vol. 76, No. 4, 2018

428

do, or do not, lead to peer co-regulation during a paired writing task? Based on illustrations from empirical data, it suggests a heuristic typology of interactive dynamics, some of which could foster, or not, peer learning. Furthermore, it explores which types of dynamics would call teacher intervention in order to involve pupil pairs in more constructive processing while undertaking together the writing task at hand.
\end{abstract}

\title{
Methodology of Research
}

\section{General Background}

The research took place in one primary school in Geneva, which demographics matched the average level of the district. An original instructional design was created for the purpose of this research (Lehraus, 2010, 2015), which has been approved by the committee of ethics for research in public schools. Two cooperative learning interventions, aimed at developing both cognitive and cooperative skills, were conducted and observed in two classes (Grade 2, age 7-8). Each intervention was composed of eight tasks in cooperative paired writing, which integrated a novel cooperative skills training tailored for its inclusion into the writing tasks, and co-construction of tools (material resources) for writing. The interventions were conducted in autumn and spring of the same school year over a period of six weeks each.

\section{Sample of Research}

The interactions of four target learners in each class, working in pairs with gender and writing-level balanced classmates, have been videotaped throughout both interventions (16 tasks, 26 hours in sum). Focused on paired teamwork, analyses have been carried out in order to document peer interactions at the end of the whole classroom-intervention. Therefore, analyzed data include only the moments, but all the moments when learners were supposed to work together without teachers' help or supervision.

\section{Instrument and Procedures}

Three types of analyses have been carried out on learners' interactions: 1) global quantitative analyses, focused on how pupil pairs engaged in assigned tasks; 2) in-depth qualitative analyses, in order to deepen understanding of this global functioning; 3) statistical analyses, aimed at unraveling the complexity of social, cooperative and cognitive dimensions of interactive dynamics (Lehraus, 2015). Here the focus is on in-depth qualitative analyses.

\section{Data Analysis}

For in-depth analyses, recorded data have been transcribed in detail and subdivided into episodes ( $\mathrm{N}=293)$. Each episode has been coded with a novel multifaceted coding system, which has been elaborated and adjusted to the data (Lehraus, 2010, 2015). Four pupil pairs' momentto-moment interactions were examined in order to analyze the qualitative features of interactive processes in light of three dimensions (social, cooperative and cognitive). For the social dimension, coding categories have been inspired by an analytical framework for qualitative analysis of learners' interactions (Kumpulainen \& Mutanen, 1999), and adjusted according to methodological outlines for examining effects of cooperative skills trainings (Gillies, 2000). For the cooperative dimension, coding categories have been derived from an existing model (Baker, 2002). For the cognitive dimension, the coding categories have been developed in a 'bottom-up' way, for being best suited to the nature of the data. These three closely linked dimensions have been treated separately for analytical purpose, and in each dimension, several indicators have been defined in order to code each episode. All the categories and indicators 
have been elaborated and refined through iterative processes in collaboration between three

In the social dimension, four indicators have been developed consistently with the trained cooperative skills: listening (e.g., looking at the partner, not interrupting the partner while speaking); dialogue (e.g., questioning the partner, explaining each one's point of view); engaging (e.g., helping the partner, sharing materials); relational climate (e.g., behaving respectfully, speaking with a nice tone). Combination of codes across these four facets allowed rating of each episode as reflecting globally positive, negative or neutral social behavior.

The cooperative dimension has been considered in light of three facets (Baker, 2002): degree of symmetry (e.g., equivalent contribution to the task from both partners), degree of agreement (e.g., explicit or implicit agreement about completing the task), and degree of alignment (e.g., focusing on the same aspect of the task). Combining of codes did result in various forms of cooperation derived from Baker's model. Lastly, each episode has been rated as reflecting effective (aligned) or apparent (not aligned) forms of cooperation.

For the cognitive dimension, three indicators have been developed about young learners' task undertaking: use of external resources (e.g., checklists, blackboard); task treatment (e.g., cognitive elaboration on writing, task management), and task evolution (e.g., completing, correcting).

\section{Results of Research}

Firstly, several extracts of pupil pairs' interactions in a writing task are presented to illustrate different associations of codes in social and cooperative dimensions, so as to describe the features of these episodes' interactive dynamics. Secondly, these emerging dynamics are examined in order to perceive to what extent they seem constructive for peer learning. Finally, these dynamics' potential is explored, in order to detect potentially informative indicators showing a need for teacher intervention.

\section{Social and Cooperative Features of Interactive Dynamics}

During the task of paired writing of an informative text about cats, following excerpts reflect different interactive dynamics taking place between 7-8 years-old learners. Extract 1 shows positive social behavior associated to effective cooperation between Ben and Aude ${ }^{1}$.

$\begin{array}{ll}\text { Extract } 1 \\ \text { 1. } & \text { BEN } \\ \text { 2. } & \text { AUDE } \\ \text { 3. } & \text { BEN } \\ \text { 4. } & \text { AUDE } \\ \text { 5. } & \text { BEN } \\ \text { 6. } & \text { AUDE } \\ \text { 7. } & \text { BEN } \\ \text { 8. } & \text { AUDE } \\ \text { 9. } & \text { BEN }\end{array}$

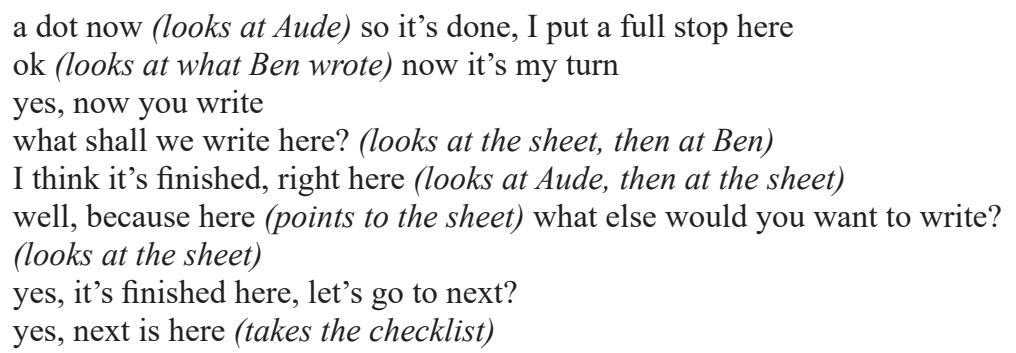

In this episode, positive social climate is combined with effective cooperation, as both learners listen to each other and are aligned on the same topic in communication. Such interactive dynamic leads them to agree that one of the text's parts (about cats' behavior) is already completed, so they decide to write a phrase suited for the next part of the text (about cats' feeding), as expected. Learners display on-task focus and also mutually co-regulate their choice of what to undertake at the moment, in order to continue completing the writing task. The interaction helps them to proceed correctly and thus can be seen as a supportive peer coregulation within the cognitive task.

$1 \quad$ Learners' names have been changed and transcripts have been translated from French. 
Katia LEHRAUS, Géry MARCOUX. Co-regulation processes within interactive dynamics: Insights from second graders' cooperative writing

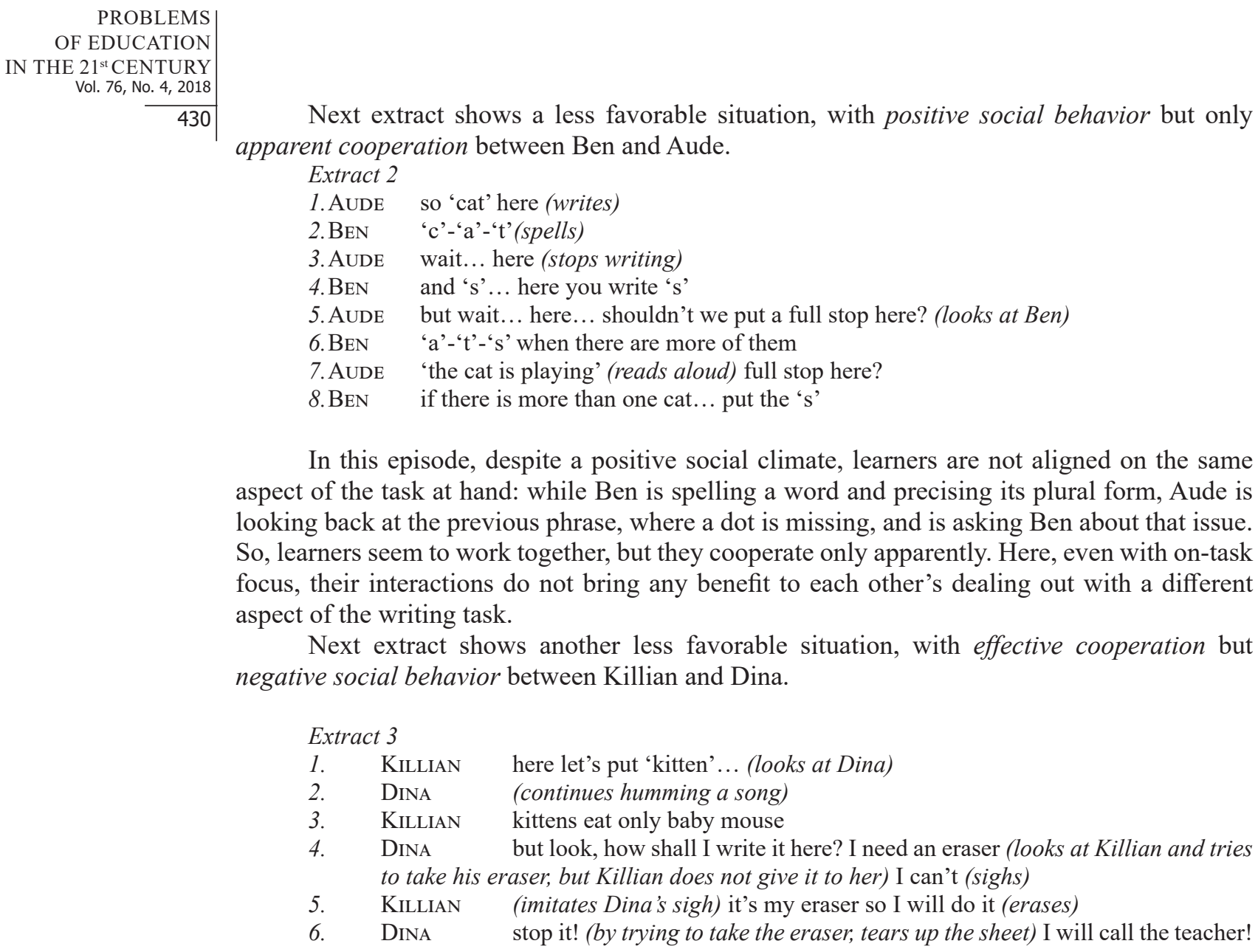

In this episode, negative social climate, even if associated with effective cooperation (the alignment being reflected by learners both wanting to write a phrase), does not lead to on-task focus and writing, hence this dynamic prevents learners from making the most of this interactive setting's potential. This excerpt illustrates a frequent problematic peer functioning, showing an arising conflict and off-task behavior, which meets usual teachers' doubts about efficacy of groupwork practice. Such interactive dynamic seems detrimental for task completing and peer learning, as well as for these learners' relationship.

Next extract shows another not favorable situation, with negative social behavior as well as apparent cooperation between Habib and Lara.

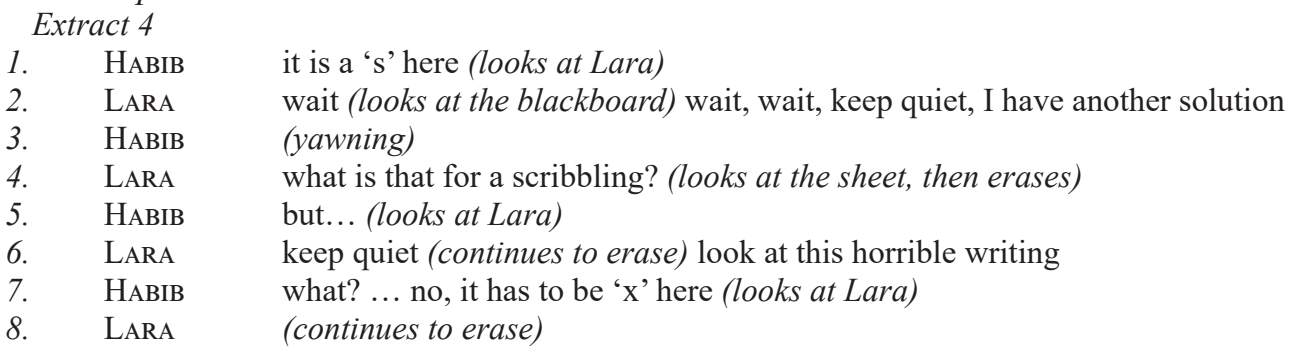

In this episode, the negative social climate is combined with apparent cooperation, as Lara is dealing with the quality of Habib's handwriting while he is trying to talk about the final letter of a previously written word. The learners are not aligned on the same topic in communication, thus this dynamic does not allow them to correct together the plural form (' $\mathrm{x}$ ' $v s$. 's') of the word. Besides, Lara's disrespectful behavior in this episode probably results in an unpleasant teamwork experience for both learners. 
In the light of the presented illustrations, it is noticeable that some of these dynamics seem to offer better conditions for peer learning than others. Following this path, insights gained from whole in-depth analysis have led to combine social and cooperative dimensions, so as to suggest a tentative typology of interactive dynamics: dynamics favoring learning (featuring positive social behavior linked to effective cooperation) and dynamics not favoring learning (characterized by negative social behavior associated to apparent cooperation). These two types of dynamics are now explored with regard to pupil pairs' undertaking of the cognitive dimension in writing and the impact on task evolution.

\section{Dynamics Not Favoring Learning and Task Evolution}

Assuming negative social behavior to be detrimental for learning because of high potential of non-constructive conflicts and disrespectful attitudes likely to result in off-task behavior ( $c f$. extracts 3 and 4), these situations obviously need to be teacher-regulated. Such regulation should take place at the contextual level on the classroom situation's features (e.g., by emphasizing the cooperative facet of teamwork structure). If not adjusted at this level, regulation is needed through teacher-pupil interventions at teamwork setting's level, where such dynamics are quite easily perceived by the teacher and usually quickly managed. However, it could deprive other learners of teacher intervention, if needed for task issues. This could happen with dynamics that are not so easily spotted from teacher's overall standpoint during teamwork settings, like when learners' social behavior is positive, but their cooperation only apparent ( $c f$. extract 2$)$. In this research, overall negative social behavior concerned less than $25 \%$ of episodes (67 out of 293 ).

\section{Dynamics Favoring Learning and Task Evolution}

Dynamics favoring learning, which means episodes coded with both positive behavior and effective cooperation (134 episodes out of 293, which is not far from half of the whole), show diverse features with respect to the writing task. Most of them display peer co-regulation, such as following extract, where Aude and Ben jointly search ideas to write about cats' behavior.

$\begin{array}{ll}\text { Extract } 5 \\ \text { 1. } & \text { AUDE } \\ \text { 2. } & \text { BEN } \\ \text { 3. } & \text { AUDE } \\ \text { 4. } & \text { BEN } \\ \text { 5. } & \text { AUDE } \\ \text { 6. } & \text { BEN } \\ \text { 7. } & \text { AUDE } \\ \text { 8. } & \text { BEN } \\ \text { 9. } & \text { AUDE } \\ \text { 10. } & \text { BEN }\end{array}$

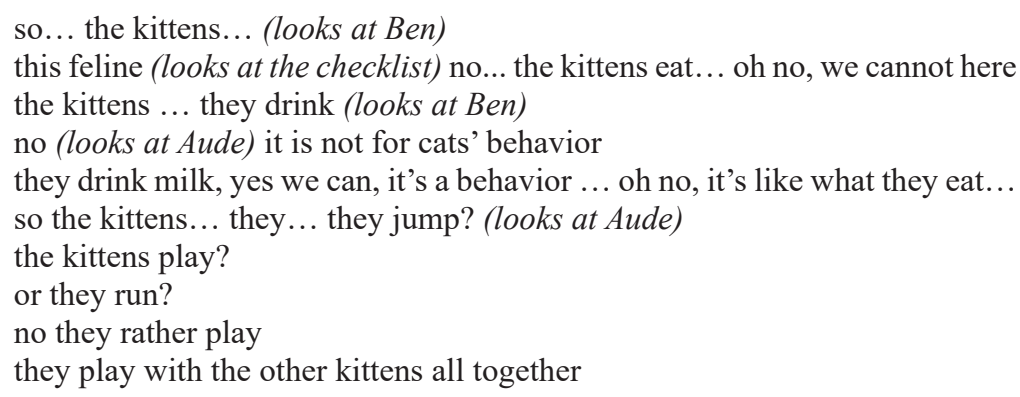

In this episode, careful listening to each other's proposals leads both learners to react to the partner's idea with a more external posture than it would be towards one's own idea, so they are able to examine critically the relevance of the proposals for the cats' behavior theme. The positive social climate allows them to share their proposals kindly without making fun of each other's ideas, and to stay aligned on the same issue in dialogue, thus cooperating effectively. These conditions can favor mutual listening and taking into account each one's ideas in order to agree for choosing the most relevant one. This episode also leads to a positive evolution, as it allows a correct peer co-regulation focused on the writing task.

Ben and Aude do not need the checklist to regulate the choice of what they decide to write, as well as they do not need teacher's help nor supervision. Yet they take profit of each other as a dialogue partner, which stimulates generation of several ideas and allows them to 
Katia LEHRAUS, Géry MARCOUX. Co-regulation processes within interactive dynamics: Insights from second graders' cooperative writing

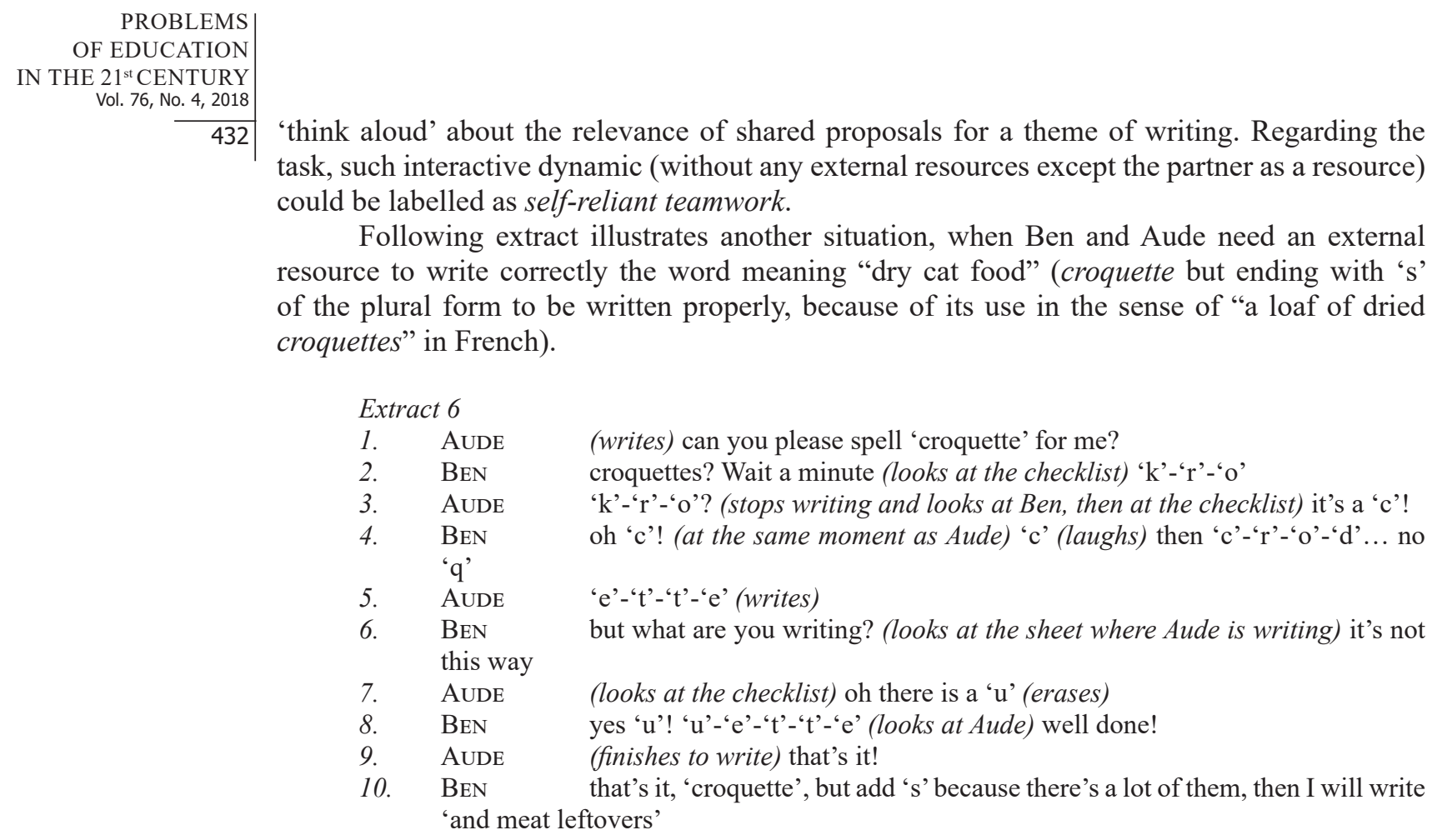

432 'think aloud' about the relevance of shared proposals for a theme of writing. Regarding the task, such interactive dynamic (without any external resources except the partner as a resource) could be labelled as self-reliant teamwork.

Following extract illustrates another situation, when Ben and Aude need an external resource to write correctly the word meaning "dry cat food" (croquette but ending with ' $\mathrm{s}$ ' of the plural form to be written properly, because of its use in the sense of "a loaf of dried croquettes" in French).

This episode shows how frail young learners' writing competence is, and how useful for them an external resource (here a checklist) can be. It demonstrates also how demanding is handwriting at this age, from a cognitive load viewpoint. In order to select relevant information for writing, needed attentional processes to achieve a complex task are carried out by both learners, each of them performing or controlling only a part of a distributed undertaking. Here, it means selection of written information on a material resource, transfer of graphic characters through handwriting and phonological spelling. Errors in spelling (' $\mathrm{k}$ ' instead of ' $\mathrm{c}$ ' on phonological level, and 'd' instead of 'q' on graphological level) show learners' difficulty to differentiate comparable information.

By dialoguing upon these issues, learners practice co-regulation in writing, which could help them to progress in selecting information. Additionally, as all these issues are linked to learners' knowledge of written language, moment to moment peer co-regulation could help them to develop metalinguistic competences. With regard to the task, interactive dynamics where learners jointly proceed with autonomous use of an external resource could be labelled as autonomous teamwork.

Following extract illustrates a less autonomous situation, as Ben and Aude cannot resolve an identified problem through neither dialogue nor external resource use, thus needing teachers' help.

$\begin{array}{ll}\text { Extract } 7 \\ \text { 1. } & \text { AUDE } \\ \text { 2. } & \text { BEN } \\ \text { 3. } & \text { AUDE } \\ \text { 4. } & \text { BEN } \\ \text { 5. } & \text { AUDE } \\ \text { 6. } & \text { BEN } \\ \text { 7. } & \text { AUDE } \\ \text { 8. } & \text { BEN } \\ \text { 9. } & \text { AUDE } \\ \text { 10. } & \text { BEN }\end{array}$

'i'-'n'-'k' (spells while looking at the checklist, where verbs are listed in the infinitive form)

(finishes to write) done, 'to drink' (reads aloud) and now 'milk' wait, here you wrote 'to drink' (looks at Ben) cats are drinking! milk (looks at Aude) but it's written 'drink' wait, wait (reads aloud) 'cats to drink'... that doesn't mean anything (erases) (looks at the checklist) should I call the teacher? drink, drinking... (looks at the checklist with Aude) wait (points to the checklist) there's only 'to drink' here but it's not ok to write (reads aloud) 'cats to drink milk' (rises his hand) let's call the teacher 
In this episode, Ben and Aude are confronted to the necessity to conjugate a verb but they find only its infinitive form in their checklist. By mutual controlling and reading aloud, they find out that what they wrote is not correct but seem unable to adjust it. As they both want to write the text correctly, they call the teacher for assistance. The interactive dynamic in this episode, where learners discuss about the issues of the task and use external tools for this purpose, could be considered as autonomous teamwork. However, regarding the task evolution and the necessity of teacher help to resolve the problem at hand, this episode is at last labelled as dependent teamwork.

The three latter illustrations ( $c f$. extracts 5,6 and 7) demonstrate various subtle interactive dynamics, where young learners display constructive peer co-regulations in complex and costly writing tasks. Considering that teacher regulation of interactive dynamics that are not favoring learning could be realized at contextual level by structuring classroom situations, teacher regulation during settings could then become a lighter and more rewarding task. Teachers' main purpose would then be to detect various indicators of dependent teamwork dynamics, in order to intervene in groups needing assistance on task.

\section{Discussion}

Illustrations of young pupil pairs' interactions in writing have shown two types of interactive dynamics, with regard to potential dealing with the cognitive aspects of a task: dynamics favoring learning and those not favoring learning. Knowing that effectiveness of teamwork is determined by the extent to which members can clarify their own understanding by asking and answering questions and build upon each other's contributions (Boruvkova \& Emanovsky, 2016), dynamics composed of positive social behavior associated to effective (aligned) cooperation seem to offer the most appropriate conditions for learners to benefit from interaction in a peer co-regulation perspective.

With respect to the impact of interactive dynamics on task evolution, illustrative extracts had reflected diverse forms of teamwork, regarding how efficiently pupil pairs could achieve a writing task through peer co-regulation only (in so called self-reliant teamwork), with addition of supportive tools (autonomous teamwork) and with teacher assistance if needed (dependent teamwork). As shown in the design of the classroom-intervention (Lehraus, 2010, 2015), teacher action has first begun at a contextual level (Allal, 2015), by structuring classroom situations with cooperative learning, cooperative skills training and co-construction of supportive tools for writing. Contextual regulation at this level can be seen as a first step to lessen negative social climate and off-task behaviors during peer learning settings, and hence set conditions for selfreliant and autonomous teamwork. Consequently, teacher would gain availability for detecting subtler interactive dynamics such as apparent (non-aligned) cooperation and, more generally, dependent teamwork.

Episodes of dependent teamwork have shown that second graders (7-8 years-old) may be less skilled than older ones in argumentative competence, thus their interactions may not have enhanced group performance as much as fifth graders' discussions (10 years-old) did in another research (Trouche et al., 2014). Such findings call for further exploration on how to improve use of cognitive resources in young learners.

In this research with beginners in writing like second graders, cooperative writing seems to have alleviated the cognitive load of the task by its distribution among partners. Even selecting information during spelling has occasionally resulted in errors, which have been regulated during interaction through mutual control. Based on these empirical illustrations, learning through peer co-regulation is thus consistent with the idea of progressing "from a lack of differentiation of information, through selectiveness carried out under guidance (externally controlled), to self-regulated selectiveness" (Ledzinska \& Czerniawska, 2008, p. 83).

By dialoguing about written language, learners practice co-regulation in writing, which could help them to improve in selecting information and developing metalinguistic vocabulary. Hence aligned dialogue within effective cooperation could also foster joint construction of 
Katia LEHRAUS, Géry MARCOUX. Co-regulation processes within interactive dynamics: Insights from second graders' cooperative writing

\author{
PROBLEMS \\ OF EDUCATION \\ IN THE $21^{\text {st }}$ CENTURY \\ Vol. 76, No. 4, 2018 \\ 434
}

representations about written language, which is consistent with findings showing increase of metalinguistic content in non-native speakers' interactions (Fleuret \& Thibeault, 2016). Such interactive dynamics fostering learning are also consistent with findings showing that metalinguistic comments are impacting factors for appropriation of writing in preschoolers (Morin \& Montésimos-Gelet, 2003).

\section{Conclusions}

The small number of learner pairs is a limitation in this research, since the process of qualitative analysis is complex and time-consuming. Another specificity of qualitative research is the inability to generalize the obtained results. Nevertheless, these results may be an inspiration for further in-depth studies.

Despite these restrictions, this limited sample processed through systematic combination of precisely defined codes has allowed to shed light on interactive dynamics that are not as stimulating for peer learning as they seem to be. In terms of implications for everyday practice, teachers' global viewpoint during peer learning might be too superficial to allow them to detect what lies beneath apparently satisfactory interactive dynamics. Hence, teachers might not be aware to miss opportunities to regulate learners' learning.

Insights gained from this qualitative exploration of empirical data allow suggesting perspectives on teacher regulation during peer learning, once conditions for autonomous groupwork and dynamics fostering learning are set. Listening to young learners' emerging metalinguistic comments while they are jointly undertaking writing tasks would give teachers an access to their actual understanding and cognitive processing, which is a valuable means to fine-tune effective scaffolding.

For this purpose, an ongoing research specifically sets under examination dynamics of dependent teamwork in order to define more precisely several indicators showing learners' need for help in the cognitive aspects of a task. Such indicators could guide teachers to discriminate which groups could benefit of scaffolding interventions in order to develop learners' cognitive processing and metalinguistic competence.

\section{References}

Abrami, P. C., Poulsen, C., \& Chambers, B. (2004). Teacher motivation to implement an educational innovation: Factors differentiating users and non-users of cooperative learning. Educational Psychology, 24 (2), 201-216.

Allal, L. (2015). Le rôle de la co-régulation dans des activités de production textuelle [The role of coregulation in writing]. Lettrure, 3, 1-14.

Allal, L. \& Mottier Lopez, L. (2007). Régulations des apprentissages : Orientations conceptuelles pour la recherche et la pratique en éducation [Regulations of learning: Conceptual orientations for research and practice in education]. In L. Allal \& L. Mottier Lopez (Eds.), Régulations des apprentissages en situation scolaire et en formation [Regulations of learning in school situation and in training] (pp. 7-23). Bruxelles: De Boeck.

Baines, E., Blatchford, P., \& Webster, R. (2015). The challenges of implementing group work in primary school classrooms and including pupils with special educational needs. Education 3-13: International Journal of Primary, Elementary and Early Years Education, 43 (1), 15-29.

Baker, M. (2002). Forms of cooperation in dyadic problem solving. Revue d'Intelligence Artificielle, 16 (4-5), 587-620.

Bandura, A. (2000). Social-cognitive theory. In A. E. Kazdin (Ed.) Encyclopedia of psychology (Vol. 7, pp. 212-213). Washington DC, US: American Psychological Association.

Blatchford, P., Baines, E., Rubie-Davies, C., Basset, P., \& Chowne, A. (2006). The effect of a new approach to group work on pupil-pupil and teacher-pupil interactions. Journal of Educational Psychology, 98 (4), 750-765.

Boekaerts, M. (1997). Self-regulated learning: A new concept embraced by researchers, policy makers, educators, teachers, and students. Learning and Instruction, 7 (2), 161-186. 
Boekaerts, M. (2006). Self-regulation and effort investment. In E. Siegel \& K. Renninger (Eds.), Handbook of Child Psychology, Vol. 4. Child Psychology in Practice, (pp. 345-377). Hoboken, NJ: John Wiley \& Sons.

Boekaerts, M., \& Corno, L. (2005). Self-regulation in the classroom: A perspective on assessment and intervention, Applied Psychology: An international Review, 54, 199-231.

Boruvkova, R., \& Emanovsky, P, (2016), Small group learning methods and their effect of learners' relationships. Problems of Education in the $21^{\text {st }}$ Century, 70, 45-58.

Bruner, J. (1987/2015). Le développement de l'enfant : savoir faire, savoir dire [Child's talk: Learning to use language]. Paris : PUF.

Buchs, C., Filippou, D., Pulfrey, C., \& Volpé, Y. (2017). Challenges for cooperative learning implementation: Reports from elementary school teachers. Journal of Education for Teaching, 43 (3), 296-306.

Crahay, M., Dutrévis, M. \& Marcoux, G. (2015). L'apprentissage en situation scolaire : un processus multidimensionnel [Learning in school situation: a multidimensional process] (pp.15-49). In M. Crahay et M. Dutrévis, Psychologie des apprentissages scolaires [School learning psychology] ( $2^{\mathrm{e}}$ ed.). Bruxelles: De Boeck.

Davidson, N., \& Worsham, T. (1992). Enhancing Thinking Through Cooperative Learning. New York: Teachers College Press.

Doise, W., \& Mugny, G. (1997). Psychologie sociale et développement cognitif [Social psychology and cognitive development]. Paris : Armand Colin.

Fleuret, C., \& Thibeault, J. (2016). Interactions verbales d'élèves allophones en retard scolaire lors de résolutions collaboratives de problèmes orthographiques [Verbal interactions of non-native students during collaborative resolutions of spelling problems]. Recherches en didactique des langues et des cultures, 13 (2), 1-17. doi: 10.4000/rdlc.881.

Gillies, R. M. (2000). The maintenance of cooperative and helping behaviours in cooperative groups. British Journal of Educational Psychology, 70 (1), 97-111.

Johnson, D. W., Johnson, R. T., \& Johnson Holubec, E. (2002). Circles of learning: Cooperation in the classroom. $5^{\text {th }}$ ed. Edina, MN: Interaction Book Company.

Johnson, D. W., Maruyama, G., Johnson, R. T., Nelson, D., \& Skon, L. (1981). Effects of cooperative, competitive, and individualistic goal structures on achievement: A meta-analysis. Psychological Bulletin, 89 (1), 47-62.

Kumpulainen, K., \& Mutanen, M. (1999). The situated dynamics of peer group interaction: An introduction to an analytic framework. Learning and Instruction, 9 (5), 449-473.

Kutnick, P., Ota, C., \& Berdondini, L. (2008). Improving the effects of group working in classrooms with young school-aged children: Facilitating attainment, interaction and classroom activity. Learning and Instruction, 18 (1), 83-95.

Lave, J., \& Wenger, E. (1991). Situated learning: Legitimate peripheral participation. Cambridge, UK: Cambridge University Press.

Ledzinska, M., \& Czerniawska, E. (2008). The importance of cognitive selectiveness in the age of information flood. Problems of Education in the $21^{\text {st }}$ Century, 5, 80-86.

Lehraus, K. (2010). Développer les interactions entre élèves en situation d'apprentissage coopératif [Developing peer interactions in cooperative learning at school]. Doct. Diss., University of Geneva.

Lehraus, K. (2015). How to integrate cooperative skills training into learning tasks: an illustration with young pupils' writing. Education 3-13: International Journal of Primary, Elementary and Early Years Education, 43 (1), 55-69.

Morin, M. F., \& Montésinos-Gelet, I. (2003). Les commentaires métagraphiques en situation collaborative d'écriture chez des enfants de maternelle [Metagraphic comments in collaborative writing at kindergarten]. Archives de Psychologie, 70 (272-273), 41-65.

Piaget, J. (1975). L'équilibration des structures cognitives [Equilibration of cognitive structures]. Paris : Presses Universitaires de France.

Pianta, R. C., Belsky, J., Houts, R., \& Morrison, F. (2007). Opportunities to learn in America's elementary classrooms. Science, 315, 1789-1796. doi: 10.1126/science.1139719.

Roseth, C. J., Johnson, D. W., \& Johnson, R. T. (2008). Promoting early adolescents' achievement and peer relationships: The effects of cooperative, competitive, and individualistic goal structures. Psychological Bulletin, 134 (2), 223-246. 
Katia LEHRAUS, Géry MARCOUX. Co-regulation processes within interactive dynamics: Insights from second graders' cooperative writing

\section{PROBLEMS \\ OF EDUCATION \\ IN THE $21^{\text {st }}$ CENTURY \\ Vol. 76, No. 4, 2018 \\ 436}

Salomon, G. (1993) (Ed.). Distributed cognitions. Psychological and educational considerations. Cambridge, US: Cambridge University Press.

Sharan, S. (Ed.) (1999). Handbook of cooperative learning methods. Westport, CT: Greenwood Press.

Sharan, Y. (2010). Cooperative learning for academic and social gains: Valued pedagogy, problematic practice. European Journal of Education, 45 (2), 300-313.

Slavin, R. E. (1983). When does cooperative learning increase student achievement? Psychological Bulletin, 134 (2), 223-246.

Slavin, R. E. (1996). Research on cooperative learning and achievement: What we know, what we need to know. Contemporary Educational Psychology, 21 (1), 43-69.

Slavin, R. E. (2015). Cooperative learning in elementary schools. Education 3-13: International Journal of Primary, Elementary and Early Years Education, 43 (1), 5-14.

Topping, K. J. (2005). Trends in peer learning. Educational Psychology, 25 (6), 631-645.

Trouche, E., Sander, E., \& Mercier, H. (2014). Arguments, more than confidence, explain the good performance of reasoning groups. Journal of Experimental Psychology: General, 143 (5), 19581971.

Vygotsky, L. S. (1934/1962). Thought and language. Cambridge, MA: MIT Press.

Yarrow, F., \& Topping, K. (2001). Collaborative writing: The effects of metacognitive prompting and structured peer interaction. British Journal of Educational Psychology, 71 (2), 261-282.

Received: March 16, 2018

Accepted: June 18, 2018

Katia Lehraus

$\mathrm{PhD}$, lecturer, Faculty of Psychology and Educational Sciences, University of Geneva, UNI MAIL, CH-1211 Geneva 4, Switzerland.

E-mail: Katia.Lehraus@unige.ch

Website:https://www.unige.ch/fapse/idea/fr/equipe/lehraus/

Géry Marcoux

$\mathrm{PhD}$, lecturer, Faculty of Psychology and Educational Sciences, University of Geneva, UNI MAIL, CH-1211 Geneva 4, Switzerland.

E-mail: Gery.Marcoux@unige.ch

Website: https://www.unige.ch/fapse/idea/fr/equipe/marcoux/ 